\title{
RANCANG BANGUN PENYIRAM TANAMAN STROBERI OTOMATIS MENGGUNAKAN ARDUINO UNO
}

\author{
Putri Sekar Ayu Dutaning Pratiwi ${ }^{1}$, Citra Kurniawan² \\ Sekolah Tinggi Teknik Malang \\ ciputk@gmail.com ${ }^{1}$ \\ airakurniawan@gmail.com²
}

\begin{abstract}
ABSTRAK
Telah banyak teknologi canggih yang diciptakan untuk membantu manusia dalam bidang pertanian, pertanian di Indonesia memegang peran penting dalam ketersediaan bahan pangan, salah satunya buah-buahan. Buah yang memiliki konsumen tinggi buah stroberi, tapi dengan banyaknya konsumen petani stroberi masih menggunakan penyiraman yang manual, hal ini membuat petani lupa akan kebutuhan stoberi dimana tanah harus selalu dalam keadaan lembab. Maka dari itu untuk membantu petani stroberi dalam penyiraman stroberi dibutuhkan alat penyiraman otomatis dimana ada alat sensor kelembaban YL-69 yang akan menyiram disaat stroberi kekurangan air dan ditambah dengan alat sensor suhu DS18B20 yang akan membantu stroberi berada dalam suhu yang sesuai, penelitian ini bertujuan untuk mengetahui bagaimana perancangan dari alat penyiraman tanaman ini, dengan menggunakan jenis penelitihan research \& development (R\&D) bersumber dari data primer yang merupakan hasil observasi, dokumentasi, pengujian dan data sekunder berupa studi pustaka dan teori yang mendukung. Hasil dari pengukuran dapat disimpulkan bahwa stroberi tetap tumbuh pada suhu berkisar $16{ }^{\circ} \mathrm{C}$ $-27{ }^{\circ} \mathrm{C}$, selain suhu ada faktor yang mempengaruhi tanaman stroberi yaitu kelembapan tanah yang berkisar $40 \%-70 \%$.
\end{abstract}

Kata Kunci : Stroberi, Penyiram Otomatis, Arduino Uno.

\section{PENDAHULUAN}

Telah banyak teknologi canggih yang diciptakan untuk membantu manusia dalam bidang pertanian, pertanian di Indonesia memegang peran penting dalam ketersediaan bahan pangan, salah satunya buah-buahan. Buah yang memiliki konsumen tinggi buah stroberi, persyaratan tumbuh buah stroberi dengan suhu ideal yang berkisar $10^{\circ} \mathrm{C}-18^{\circ} \mathrm{C}$ suhu udara berpengaruh dalam metabolism stroberi seperti pernafasan dan fotositensis, faktor lain yaitu kelembaban tanah stroberi yang harus selalu lembab, ph tanah yang harus tetap terjaga agar terhindari penyakit-penyakit stroberi yang dapat mempengaruhi hasil dari buah stroberi.

Dari syarat tumbuh diatas dalam hal penyiraman petani masih banyak menggunakan penyiraman manual memungkinkan untuk buah stoberi rusak karena kekurangan air. tapi dengan banyaknya konsumen petani stroberi masih menggunakan penyiraman yang manual, hal ini membuat petani lupa akan kebutuhan stoberi dimana tanah harus selalu dalam keadaan lembab. Maka dari itu untuk membantu petani stroberi dalam penyiraman stroberi dibutuhkan alat penyiraman otomatis dimana ada alat sensor kelembaban YL-69 yang akan menyiram 
disaat stroberi kekurangan air dan ditambah dengan alat sensor suhu DS18B20 yang akan membantu stroberi berada dalam suhu yang sesuai

\section{METODE PENELITIHAN}

A. Jenis Penelitian

Jenis penelitihan dalam rancang bangun penyiram tanaman otomatis ini terdapat tahap-tahap dalam metode yaitu: (1) observasi; (2) desain prototype; (3) kalibrasi; (4) build prototype; (5) pengujian.

\section{B. Jenis Data}

Dalam hal ini jenis data yang digunakan penilis adalah jenis penelitian kualitatif, yang dimana data dan informasinya diperoleh dari kesimpulan secara deskriptif dan tampa menggunakan angka karena dalam perancangan ini lebih mengutamakan prosesnya.

\section{Sumber Data}

Dalam penelitian ini penulis menggunakan dua sumber data yaitu:

\section{Data Primer}

data primer dalam penelitian ini adalah perkebunan stroberi di daerah Paralayang - Batu .untuk sumber data materi tentang stroberi dan untuk sumber data observasi.

\section{Data Sekunder}

data yang didapat dari beberapa buku dan catatan yang berhubungan dengan penelitian selain itu peneliti juga mempergunakan data pendukung materi tentang stroberi, metode pengembangan dan arduino dari internet.

\section{Teknik Pengumpulan Data}

Memperoleh data yang akurat dan sesuai dengan pemeralahan dalam skripsi ini, maka penulis melakukan pengumpulan data sebagai berikut :

\section{Metode Observasi}

Menurut(Sugiyono,2012), pengamatan pada suatu objek dengan menggunakan semua alat indra dan semua ilmu pengetahuan disebut observasi, dalam metode ini digunakan untuk mengetahui informasi tentang tanaman stroberi.

\section{Metode Wawancara}

Menurut (Sugiyono,2012) wawancara yaitu pertemuan dua orang untuk saling bertukar informasi melalui Tanya jawab, dalam metode ini bertujuan untuk menggali informasi dan data tentang tanaman stroberi dengan pengumpulan data berupa interview dengan narasumber.

\section{Metode Dokumentasi}

Menurut(Sugiyono,2012) dokumentasi

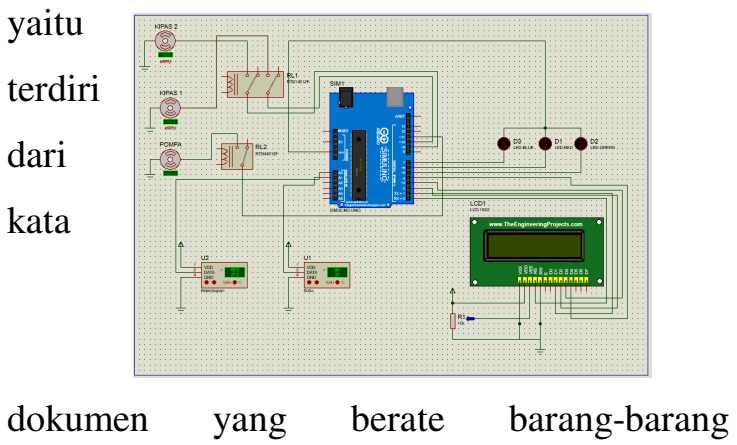
tertulis,gambar atau pun karya monumenta 
dari seseorang, dalam penelitian ini penulis mendapatkan data tertulis tentang buah stroberi.

\section{HASIL DAN PEMBAHASAN}

A. Perancangan Sistem

Perancangan sistem penyiraman tanaman ini dibagi menjadi dua, yaitu perancangan mekanik dan perancangan elektronik, perancangan mekanik meliputi pembuatan tempat dan tata letak komponen komponen seperti sensor, pengkabelan, letak pompa air dan kipas. Rangkaian mekanik dapat dilihat pada gambar 6.1.

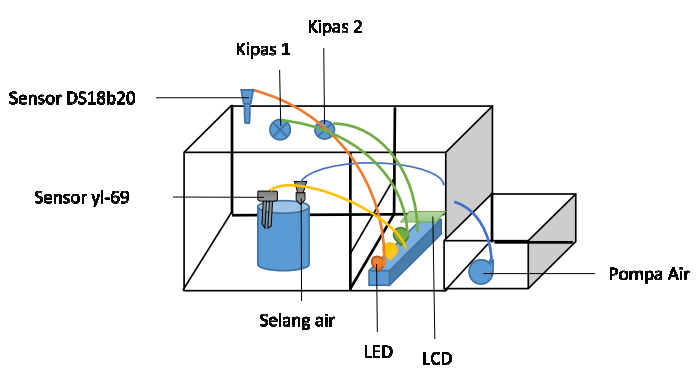

Gambar 6.1 Rangkaian mekanik

Sumber : peneliti

Perancangan elektonik meliputi pembuatan rangkaian untuk menghubungkan masing - masing komponen seperti sensor,LCD,LED, relay, kipas, pompa air. Proses perancangan dilakukan dengan menggunakan softwere Isis Proteus 8. Komponene - komponen tersebut dibagi menjadi tiga bagian yaitu: komponen imput, komponen pemroses dan komponen output. Gambar rangkaian dapat dilihat pada gambar 6.2.

Gambar 6.2 Rangkaian elektronik

Sumber : peneliti
B. Pengukuran

Dalam metode research and development $(R \& D)$ pengujian alat merupakan proses dimana alat yang dibuat apakah berfungsi sesuai dengan yang diharapkan atau tidak untuk pengujuan prototipe dilakukan dalam 1 minggu dengan menggunakan media tanaman stroberi yang berumur 1 minggu sebelum panen, proses alat penyiram tanaman,kipas 1 akan menyala jika kelembaban tanah $>70 \%$ dan akan mati jika kelembapan $<40 \%$, kipas 2 akan menyala jika suhu $>18^{\circ} \mathrm{C}$ dan akan mati jika suhu $<18^{\circ} \mathrm{C}$ lalu pompa akan menyala jika kelembaban $<40 \%$ dan akan mati jika kelembaban $>70 \%$.

C. Hasil Pengukuran

Penelitian ini menggunakan objek tanaman stroberi, dimana stroberi membutuhkan kelebaban yang harus selalu terjaga kelembabannya, sehingga perlu adanya penyiraman yang kontinyus agar kelembabanya terjaga, pengukuran sistem ini dilakukan selama 1 minggu dengan tanaman stroberi yang berumur 1 minggu sebelum panen, hasil Dari pengukuran diatas dapat disimpulkan bahwa stoberi tetap dapat tumbuh pada suhu berkisar $16^{\circ} \mathrm{C}-27^{\circ} \mathrm{C}$, selain suhu ada faktor yang mempengaruhi tanaman stoberi yaitu kelembaban tanah yang berkisar $40 \%$ - $70 \%$ dan tumbuhan stroberi tetap berbuah merah dengan sistem ini.

\section{KESIMPULAN}

Berdasarkan hasil permasalahan serta pengujian yang dilakukan oleh peneliti, maka dapat ditarik kesimpulan sebagi berikut: 
1. telah dirancangdan di buat alat penyiraman tanaman dengan desain yang sesuai peleta kan komponen dan berjalan dengan baik.

7.1.2 alat penyiraman tanaman ini dapat berjalan dengan lancar dan semua komponen berfungsi dengan baik dan stroberi dapat tumbuh dengan suhu berkisar 16 - 27 derajat.

7.1.3 Hasil dari pengukuran dapat disimpulkan bahwa stroberi tetap tumbuh pada suhu berkisar $16{ }^{\circ} \mathrm{C}-27^{\circ} \mathrm{C}$, selain suhu ada faktor yang mempengaruhi tanaman stroberi yaitu kelembapan tanah yang berkisar 40\% - 70\% dan buah stroberi dapat bertumbuh dan berbuah merah dengan alat ini.

\section{DAFTAR PUSTAKA}

Arifiyan, Grezio. Dkk. 2013. Rancang bangun system perawatan tumbuhan kacangkacangan secara adaptif pada lingkungan greenhouse dengan mikrokontroler arduino. Surabaya: Institut Teknologi Sepuluh November.

Harimurti, Triana. Dkk. 2012. Perancangan sistem penyiraman air otomatis berbasis mikrokontroler. Bandung: Universitas Telkom Dolynah, 2008. Pengaruh lingkungan tumbuh yang berbeda terhadap kualitas buah stroberi. Institut Pertanian Bogor. Bogor

Firmansyah, 2015. Proyek Robotik Keren dengan Arduino. PT Elex Media Komputindo : Jakarta

Kadir, 2015. From Zero To a Pro Arduino. CV Andi OFFSET : Yogyakarta
Agus, 2005. Petunjuk Praktis Budidaya Stroberi. PT Argo Media Pustaka : Jakarta 
